\title{
Outlining a Set of Theory-based Requirements for the Future Digital Soldier
}

\author{
Szilveszter SZELECZKI ${ }^{1}$
}

The military information scene is expanding as technology advances, and it has a fundamental impact on combat activities. It requires a high level of precision, expertise and dedication to set the right standards for military concepts and to establish a proper set of requirements of standards for military concepts, such as in NATO. Digital devices have become an integral part of the activities of the combatant soldier, as the use of modern tools makes combat activities more efficient. In a modern society, modernisation processes extend to the field of defence as well, resulting in intensive development in a growing number of countries. The requirements of the digital soldier are nowadays influenced not only by the warrior but also by those connected to him in the full information space, since a modern soldier is already an element of a network in network-centric military operations.

Keywords: digitalisation, requirement, information, soldier, NATO.

\section{Introduction}

In today's information-oriented society, the defence strategies of different nations undergo constant changes and innovations. Year after year, improvements and extensions can be seen in terms of technical equipment, procedures and methods. Perhaps one of the most prominent amongst governmental objectives is the development of modern strategic principles specifically designed for the present-day network structure related to the purposes of military innovation. During the cooperation of different arms, there is a need for continuous networking, and reliable operation of voice and data communications. Recent studies pay special attention to different activities on the battlefield. Some commentaries prefer, for example, the land forces, while others focus on other military branches. The land forces are considered to be the most common among the armed forces, and its targeted technological development nowadays clearly requires a network strategy mindset that, among other things, draws the attention of management to information issues.

Digital military concepts formulate a set of requirements specifically for the combatant. Looking back to the past, it can be seen that the military concepts of warfare went through

Ph.D. student, National University of Public Service; e-mail: Szeleczki.Szilveszter@uni-nke.hu; ORCID: https:// orcid.org/0000-0003-2891-0527 
continuous analysis since the second half of the $20^{\text {th }}$ century. Initially, they only focused on defence against grenades with regard to the capabilities of the uniform concerning shrapnel-protection, but later on, these concepts became more and more a technological issue in telecommunications, and with the spread of information technology, the continuous presence of voice and data connections became an integral part of the requirements. "Techniques for communication and computation cannot be studied in isolation: one technique for reducing communication energy usage is to perform more local processing, but this increases the amount of computation energy." [1: 57] The combat situation of an infantry soldier is probably the most common situation: a soldier performs its own combat operation with its own personal equipment and strength. The networked, modern concept of this equipment system and arsenal belongs to the digital soldier. Investigating this concept and answering the emerging questions in the present day is becoming more and more important to the armed forces, and thus its comprehensive understanding and integration may be a key issue for future armed forces, where consistent, precise definition of requirements is essential. "Digital Soldier is seeking whitepapers to include specific technologies and/or novel integration ideas." [2] Military developments bring up national and allied (e.g. NATO) requirements that also affect the digitisation of combat soldiers, so a set of requirements must be established, which serves the interests of all in the future.

\section{Defining the System of Requirements}

\section{Purpose and function}

The general aim of a digital military requirements system is to refine and upgrade the existing military equipment specifically for the combatant. In order to determine the subject in detail, it is necessary to take into account every field of activity that may be necessary in the course of modernisation. The definition of the objectives must be accompanied by the formulation of the exact purpose, which in this case contains the operational concepts of a military system. Of course, there are differences in priority between digital military objectives, which may be related to the planning and development process. In formulating the overall goal, the specific issues of the federal and national concepts complete the comprehensive elements of the system of requirements.

The definition of goals is closely linked to the interpretation and formulation of purposes. The basic purpose of digitising a fighting soldier is to enhance the soldier's information capabilities, which he or she can effectively collect, use, and transmit in the course of his or her combat activities. It is the general duty of soldiers to fight bravely and steadily in combat; to find the most expedient way to defeat the enemy, to use all available tools wisely and effectively, and to act with determination. Thus, the purpose of the aforementioned military digitisation is basically modernisation, concerning also the flexible capability of using info-communication tools which can react quickly and efficiently to changing circumstances. Improvements and upgrades are only carried out where they are needed, and therefore a precise understanding and definition of the requirements can be considered as a basic condition for establishing the requirements of the digital soldier. 


\section{The Need for Requirements}

In order to determine the exact requirements, first the fundamental effects of a given development or innovation must be examined. Digital soldier project can be termed as a general terminology and the first step in establishing an actual set of requirements is the examination of the necessity of each requirement, their possible positive and negative effects. As a consequence, the needs can be precisely delineated. It is important to have a conscious mindset that will result in deciding what is necessary and what can be judged sufficient. Obviously, there is a need for defence-related developments, because with the advancement of information technology, the activities of the soldiers must be improved to reach the highest possible standard, and the question rather arises as to what may be interpreted as necessary. This approach is associated with the practical experience and the related management opinions. Of course, the answers to questions about qualities of an innovative new info-communication system depend on many influencing factors, as there are several aspects to consider, especially the views of the participants in the network.

As for meeting the information needs, both from the perspective of the user warrior and from other actors within the network structure, a consistent set of requirements should be defined. Therefore, in digital military concepts, it is important to consider and define the boundary between what is needed and what is sufficient, because the priority values of the requirements can be determined specifically through a thorough analysis of the needs. The following types of essential requirements are required for the proper definition of requirements:

- technical requirements;

- system architectural requirements;

- system integration requirements;

- requirements for ICT (Information and Communications Technology) tools.

Finally, the aggregate data resulting from the above-mentioned necessities allows the need to meet the exact purposes and define a consistent set of requirements. The armed forces' pursuit of continual modernisation gives rise to the general need of digital military concepts, as the development of necessary and sufficient functionalities is periodically re-evaluated. Of course, revaluation is also required for practical use, as a military subsystem or sensor, for example, may not produce the expected results for a networked warrior or its associated partners. Thus, usability appears as a crucial influencing factor for the finalisation of the need, since the effectiveness of the digital military system is decided in practice, not in theory.

\section{Content of the Requirements}

The content of the system requirements includes plans, concepts and the necessary conditions for the realisation of military concepts. The specification of the content of the requirements is a logically separate part of the digital soldier project, which is at the beginning of the entire project life cycle. In defining the content of the project requirements, it is worth to pay attention to the fact that there are methodologies specifically designed for project management that can provide quite a large amount of professional help with this military 
project. Essentially, the methodologies provide some insight into the logical phases and parts of a project. Such a methodology guides the project from initial thinking to tangible results. An example of this is Project Cycle Management (PCM), which specifically promotes professional project planning.

Opinions differ on the need for methodologies, but experience from different sources makes it clear why it is worthwhile to use methodologies in a project. The best known of these reasons are:

- confused strategic frameworks;

- supply-driven projects (write a project that has money);

- poor situation analysis;

- activity-oriented planning;

- ignoring the needs of target groups;

- short term thinking;

- unexpected risks;

- inconsistency of results;

- costs are not in proportion to the benefits gained;

- lack of experience;

- immeasurable effects;

- inaccurate project documents.

Thus, the methodologies also help to define the requirements system precisely, as they place the emphasis on the importance of the detailed elaboration of the whole life cycle, the sequence, the expected results and the opportunities. Figure 1 shows the stages of the project lifecycle defined by the PCM methodology. The Digital Soldier Global Project also begins with a programming phase where leaders of nations analyse the current military situation, condition, organisational structure, function, tasks, and explore the options accordingly.

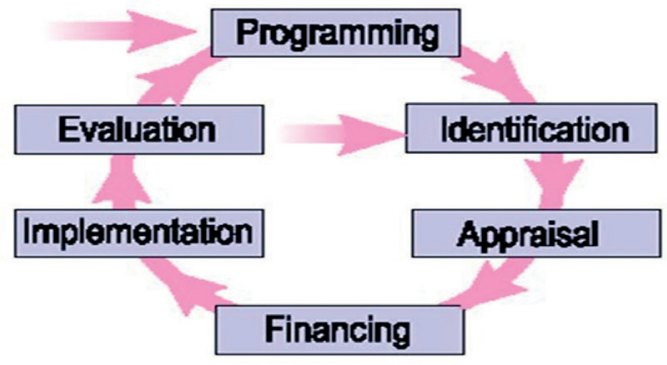

Figure 1. The project lifecycle proposed by PCM. [3]

Of course, when developing the requirements of digital military concepts, the standardised solutions used by NATO forces must be taken into account and the experience gained so far should be utilised. The content of the requirements may be determined on the basis of the following essential aspects:

- consideration of NATO's requirements;

- definition of specific requirements;

- allocation of responsibilities to requirements. 


\section{Feasibility}

In the realisation of the digital soldier project, it is important to emphasise the conscious attitude of the combatant soldier that he/she is a system component. In this way, the information system can be used simultaneously by the combatant and other users in the network to receive or send data. "Other users" include other combat soldiers and members of upper management / superiors. It is therefore about implementing a complex system that fully integrates the combatant's activities, where the designation of requirements requires a high degree of complexity.

When talking about the points to be considered during the definition of the set of requirements, I suggested observing NATO's relevant requirements. As to the feasibility of the requirements, various NATO documents may be linked here, including:

- NATO Standardization Agreements (for instance STANAG 5048);

- NATO Allied Engineering Publications (for instance AEP-76 VOL 1);

- NATO Allied Data Publications (for instance ADatP-34);

- NATO Allied Tactical Publications (for instance ATP 3.2.2);

- NATO Allied Joint Publications (for instance AJP-6).

From the aspect of the feasibility of the plans, it is essential to consider the possibilities to fit them into the order of standards, announcements, procedures, methodologies and to make modifications and corrections in the definition of the requirements based on their contents. For example, the digital military concept should take into account NATO's information communication requirements for different hardware and software designs, with particular reference to interoperability, which obviously has a high priority among member countries. With regard to interoperability, interface as a concept extends to info-communication tools, and more specifically to the communication between all information-based devices. [4] From the point of view of info-communication, compliance can be interpreted on the basis of three essential aspects:

- data link level compliance;

- voice connection level compliance;

- global, system-level compliance.

Thus, the feasibility of digital military systems requirements is related to the imaginative tools that include various system link controllers, data and voice model structures, protocols. These tools must cooperate with each other during operations, that is, they must be interoperable. Some of the aforementioned NATO standards serve this purpose specifically, increasing allied efficiency and continuous cooperation between current information and network-oriented military forces. Thus, several official NATO publications deal with issues about requirements to achieve interoperability. "NATO's interoperability policy defines the term as the ability for Allies to act together coherently, effectively and efficiently to achieve tactical, operational and strategic objective." [5]

Figure 2 shows NATO's call for why it is necessary and worthwhile for member states to use published standards in their development. 


\section{NATO COMMITMENT TO OTAN IMPLEMENTATION}

\begin{tabular}{|c|c|c|c|}
\hline $\begin{array}{l}\text { A complete picture and } \\
\text { periodic qualitative and } \\
\text { quantitative } \\
\text { assessments of } \\
\text { implementation, } \\
\text { including by Partners, } \\
\text { are required }\end{array}$ & $\begin{array}{l}\text { Implementation of } \\
\text { standards is the } \\
\text { indispensable national } \\
\text { contribution to NATO } \\
\text { standardization }\end{array}$ & $\begin{array}{l}\text { Implementation of } \\
\text { standards by individual } \\
\text { Allies is a relevant and } \\
\text { useful output metric } \\
\text { offering a qualitative } \\
\text { indication of the } \\
\text { development of the } \\
\text { interoperable } \\
\text { capabilities needed to } \\
\text { bolster Alliance } \\
\text { readiness and } \\
\text { responsiveness }\end{array}$ & $\begin{array}{l}\text { NATO shall promote } \\
\text { transparent national } \\
\text { implementation of } \\
\text { standards with the } \\
\text { understanding that } \\
\text { standardization is, in } \\
\text { principle, voluntary for } \\
\text { Nations and that } \\
\text { implementation is a } \\
\text { national decision with } \\
\text { importance for NATO's } \\
\text { ability to fulfill its missions }\end{array}$ \\
\hline
\end{tabular}

Figure 2. NATO's call about standards implementation. [6: 10]

Therefore, taking standards into account alone provides guidance for digital military concepts. Whether it is about relationship models, structures, hierarchies, or any specifications in management and control systems, they are all essential parts of the requirements. For example, NATO STANAG 4677 discusses these parts, while NATO AEP 76 already addresses systematic deployment, prioritising network concepts. Thus, these standards all contribute to the realisation of the requirements of basic digital military concepts, where the information exchange focuses on the activities of the fighting soldier, all at joint operation level.

Information has a growing power in the modern world, thus affecting the feasibility of innovative military projects. Therefore, adapting to the information space must also be the central element of the feasibility of digital military concepts, since the ability to use information can fundamentally influence a combat activity. "The principal needs of the Army for tactical command, control, and communications (C3) applications fall into two categories. First, to enhance the lethality of the Future Soldier, advanced information technologies are needed to insure reliable, wideband, networked communications over an area commensurate with evolving battlefield environments. Second, for the Future Soldier 2030 to maintain information dominance, situational awareness data set must reflect higherlevel tactical internet and global command and control system network intelligence.” [7: 13]

Feasibility in military terms may also depend on answering information security issues, since a high level of information activities is the core element of military operations. "Most 
commercially available systems do not address relevant military needs, typically lack the validated algorithms that make real time computed information useful, and are not open architected to be integrated with the soldier technological ecology.” [8: 1147] The enemy wants to get the most up-to-date information; thus, its protection and management requires the most effective procedures and methods. "The sharing of the information wins the fight, not the biggest or best bullet. We are looking at a soldier as a communications intelligence platform, not just a person with a weapon system.” [9] The same goes for counter-activities and support activities. Information processing issues therefore, like interoperability, also require high priority, mature solutions concerning the feasibility of requirements. When implementing the requirements for a fighter's military info-communication activities, it should be taken into account that the soldier:

- collects information;

- stores information;

- processes information;

- transmits information.

Information capabilities therefore play a crucial role in defining the set of requirements. These require a detailed, prioritised development. The hardware and software differences between countries also appear to be decisive factors in the feasibility of requirements for digital military concepts. There will be a lot of questions and answers from participants involved in the implementation of the requirements so that the digital soldier project can begin to be built on the right specification using the information communication capabilities at its disposal.

\section{Applicability}

The applicability of the requirements is largely shaped by the experience gained from the above mentioned practices, which differ in the armies of different countries and represent different values. It is important to note that the timeliness of the requirements plays an important role in the usability issues, as the decision-makers need to make well-founded decisions about the future, generally on an annual basis. For example, an American article says: "Army HQ has a vision for the future soldier of the 2020s that exploits rapid advances in technology to revolutionise the dismounted soldier's equipment in its entirety." [10] Which means that they are planned to be used for a relatively short period of time, a few years after which the definition of long-term time will be reassessed. The usability is guided by design ideas and suggestions for the most efficient solution. Design solutions should take into account military operational requirements, which place a high priority on practical aspects of attack and defence. The requirements may be applied for military purposes in the following areas: "Command and control, lethality, mobility, survivability, sustainability." [11: 127]

The various services involved in the activities of a combatant may be active or passive, which of course also have to be organised in relation to operational issues. These functionalities may change over time and space, depending on the combat situation, including the information they provide. 
Focusing on networking through the example of the American FIST program, in response to changing circumstances, the following is stated: "The network system will reroute automatically to allow continuity of operation when a communications link is broken, for example when a soldier moves over a hill or ridge.” [12] Information must be managed in a centralised system that requires a set of hardware and software that can use that information for further operations. By thoroughly defining the requirement types mentioned above, the following functionalities required by the digital military concept can be implemented:

- positioning, target marking system;

- digital voice and data communication;

- management support system;

- energy supply system;

- sensory monitoring system;

- weapons system;

- clustered information system;

- modern uniform solutions.

\section{Imaginations}

\section{Capability concepts}

At first glance military digitalisation ideas seem to be what digital communication is about, but in most cases they consist of a much broader, larger set. In today's digital world, more and more advanced and higher-level services can be imagined and demanded. When defining military info-communications concepts, one must consider the set of properties that include the info-communication service that is exactly needed. During normal operation, it is important to understand when, where and how it is expedient to use a particular service.

In relation to NATO, the member countries have different titles and ideas for the future digital soldier. For example, Land Warrior in America, Future Integrated Soldier in Great Britain, Gladius in Germany, Combatiente Futuro in Spain and FELIN in France. In essence, each member country strives to adopt its own and the allied ideas for its project, which will raise combat soldier capabilities to a higher level. These ideas and projects consist of several basic requirements which can be defined as a kind of modernisation capability. These are as follows:

- info-communication capability;

- armed ability;

- survivability.

Military developments are progressing over time to develop a more modern mobility capability in these capability areas. Info-communication abilities can be linked to the emergence of novel concepts aimed at networking the combatant's information capabilities, thereby expanding individual abilities. A certain device capable of collecting, storing, processing and transmitting information can be classified here. Examples include radios, sensors, display units, storage and distribution devices. With regard to radios, 
tactical radios with a sufficient bandwidth and capability of transmitting both voice and data to appropriate range come into the forefront.

Radios capable of IP-based data transmission are a major step in the development of digital communication, the integration of which can be interpreted as a fundamental factor. To optimise the use of the data channel, the most appropriate channel access protocols should be used. In this way, radios capable of these are preferred, as they may meet the requirements that can be expected in the future. General ideas about sensors include information about different states and active signals. This includes, for example, active detection information, which can occur in light and sound. Of course, in the light range, laser and infrared solutions are the ones that can be used for target designation, while the sound range can provide the information. This information would be monitored by a clustered sensor array that would provide the information to the warrior and the senior leadership within a short period of time. Blue Force Tracking is typically an information service that requires up-to-date information to function. "The section leader is equipped with BMS (Battle Management System), a veritable nexus for communication networks, contributing to a fully digitized battlefield network. Hosted in a lightweight portable computer adapted to military environments, it allows the leader to control platoon or squad manoeuvres, give orders to and collect intelligence data from every soldier on the battlefield. Built around a processing module and a remote touch screen, the computer allows leaders to exchange information (data, images, video, virtual maps) and communicate using radio networks.” [13]

Weapon-related issues and the requirements that apply to them are essentially dependent on technical parameters. The information capabilities of the various $7.62 \mathrm{~mm}$ and $5.56 \mathrm{~mm}$ assault rifles could primarily be combined with a subsystem that can, for example, designate a target and process information from another subsystem for further use. In this context, for example, the development of target illumination methods and the exact specification of its requirements may be necessary. "In the future, soldiers will be equipped with a weapon system that would allow them to identify a target, and then simply to aim and shoot. They will receive relevant data, and will be equipped with night vision equipment.” [14]

In terms of survival, defence objectives come to the forefront, with the help of which the soldier manages and solves situations occurring in the battlefield. An article on a German concept reads: "The body armour component is designed for protection from detection, biological and chemical agents and extreme climatic conditions. It includes flame retardant equipment, a ventilation shirt and insulating layers to stabilize body temperature, and ballistic protection.” [15] Raising survivability to a higher level is highly dependent on the magnitude of the defence options.

With this in mind, the following solutions can be considered:

- modern uniforms;

- technical devices providing protection:

- against designations;

- against atomic, biological and chemical weapons;

- against landmines;

- heavy-duty kits. 


\section{System Implementation Ideas}

Different ideas can be classified according to their abilities. Referring to the breakdown as needed, detailed operational requirements can be broken down into technical, system architectural, system integration, and info-communication schemas.

The technical requirements for the digital soldier determine the basic information task systems in which both the user and the service provider appear. The exact definition of the expected capability of a technical device is essentially provided by the technical requirements. Sensor-related and other communication parameters, such as size, fit, design and other technical values and definitions, are also required for the system linked to the infocommunication network. "Digital soldiers also need to interconnect their sensors, tactical computing and communication devices. In order to achieve full wideband connectivity, a data switch needs to be a real wideband communication protocol.” [16] It is an important criterion that parameters must be effectively reflected in military practice.

From an architectural point of view, capabilities can be divided into different levels. For example, a distinction can be made between some basic and some complementary skills. These levels can be defined in steps, or expanded to more specific sub-levels. The realisation of all these will result in a complex system of ideas. You can also define a priority difference for stepwise deployment. An imaginary structure similar to this is shown in Figure 3, to illustrate a step-by-step layout in the field of info-communication capabilities with some examples that can be expanded to meet customer needs. The architectural approach to the project is necessary because it will result in a systematic consideration and development of system components based on each other. For example, the concept of a helmet camera can only be tested if its image can be transmitted to a display device. Thus, in this case, first the proper functioning of the camera and its information transfer capability must be ascertained, and this must be followed by the proper functioning of the information display unit.

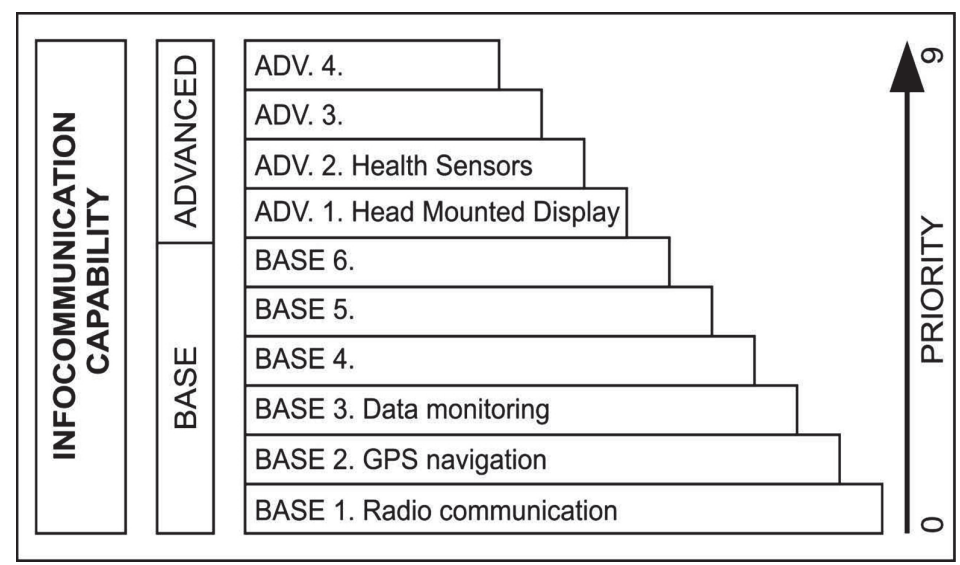

Figure 3. Illustrated structure of the info-communication capability. [Created by the author.]

System integration concepts focus on the integration of devices to be used in the digital military system. In this requirement, an imaginary list should be created which should 
include the relationship between the devices, communication, control levels, representations and other features, in which the interoperability mentioned above will also play a role. At the simple logical level, the system integration can be imagined in four steps as shown at Figure 4 below. The processes must be detailed and specified that can take very-very long time.

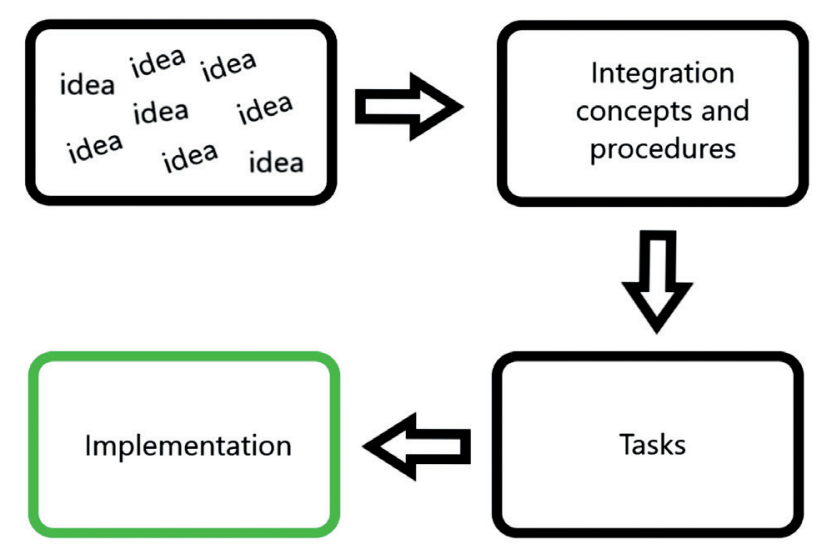

Figure 4. Simple way from ideas to implementation. [Created by the author.]

So, the list should include the following main integration concepts and procedures:

- selecting partners and ensuring continuous communication;

- precise definition of development tasks based on the technical requirement;

- providing a development background for information concepts between components;

- ensuring cooperation between developments;

- proper handling and serial-numbering of prototypes;

- developing tests to be applied to prototypes;

- preparation of documentation containing full applicability;

- continuous monitoring of processes, allocation of responsibilities.

Info-communication tasks, expectations and their implementation ideas have to be defined for the devices. In application terms, the following types of devices are generally required:

- communication device;

- interfacing / distribution device;

- power supply device;

- navigation device;

- display device;

- detection device;

- data collection tool.

Applicable tools also need to consider their software background and capabilities for adapting devices to the appropriate requirements, resulting in the most efficient implementation from a technological perspective. Figure 5 shows the previously mentioned project, called "Land Warrior" in American terminology, showing a future warrior with his toolbox. 


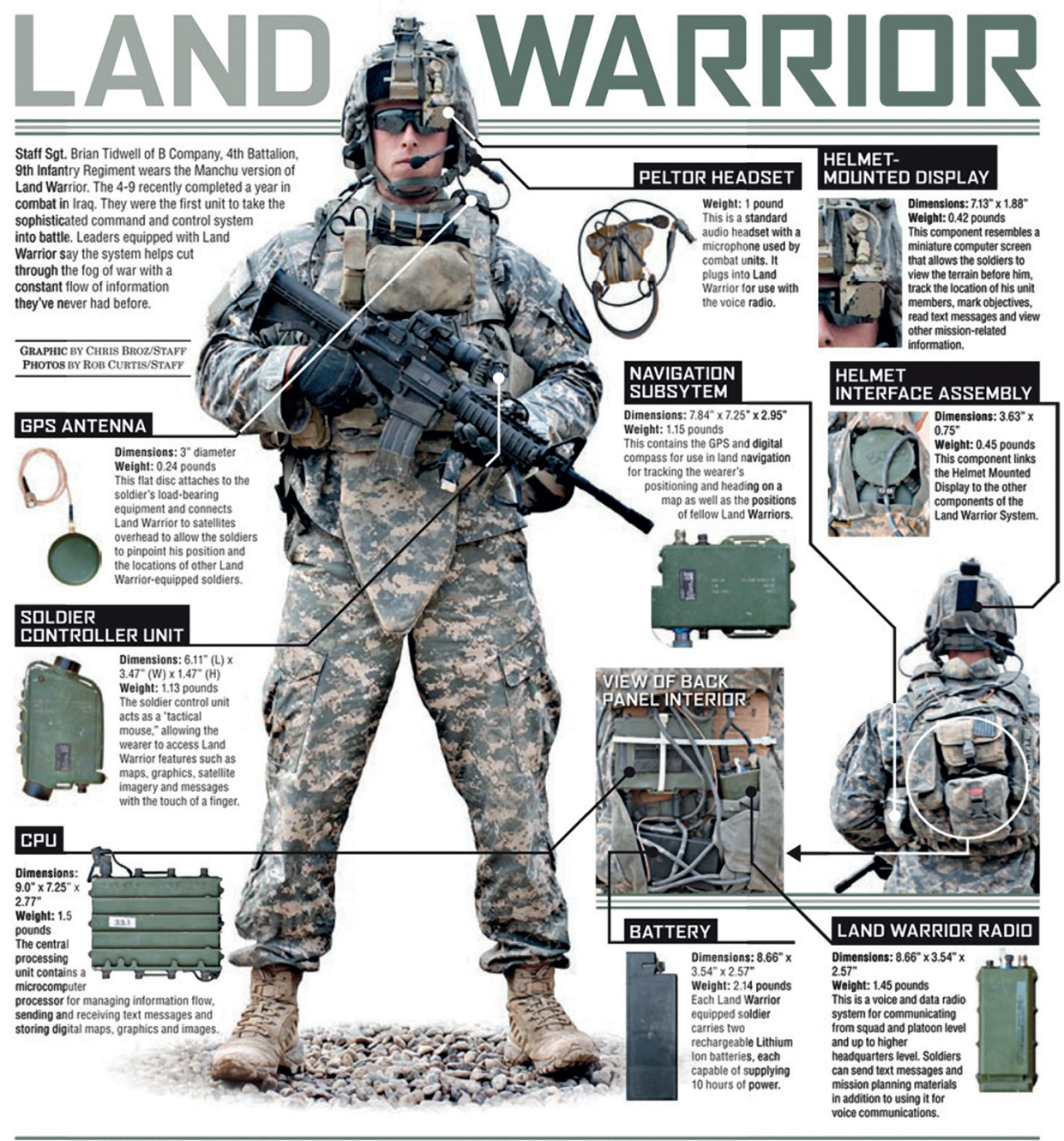

Q 2008 Army Times Publishing Co.

Figure 5. The American future warrior conception. [17]

Each of these devices must be examined and a set of practise-based and detailed requirements must be set out. A digital military network system can only be realised if all the hardware and software components that one wants to apply have complete, accurate ideas, analysis, and evaluation. All of these can help to create the most effective system of claims about the digital soldier. 


\section{Summary}

The Digital Soldier is a global military concept that provides support to combat soldiers using the most up-to-date, state-of-the-art technology. This program is specifically focused on the combat situation when a combat soldier performs his task using his personal equipment. When designing and specifying requirements, it is essential to consider the user environment, but network-oriented concepts must also be met. For the military, the timeliness of information always plays an important role, as it is either armed or allmilitary, and knowing the exact real-time combat situation is invaluable. The concept of a digital soldier is made up of several sets of capabilities that can result in a modern warrior equipped with competitive technology. Injection and development of info-communication capabilities is an extraordinary development, but weapons and other supplies and tools are also undergoing major changes in military system organisation.

There are many aspects that need to be worked out in detail in the requirements, and different methodologies or information from experience can help with their quality. A kind of specialisation process is already under way within NATO member states (e.g. monitoring, reconnaissance and target-designation tools independent of time of day or weather). As a component of the system, the capability of monitoring, displaying, and transmitting data on the physical and health status of soldiers during combat has emerged as a requirement, but the specific development process has not yet begun. Traceability of friendly forces is now becoming a basic requirement in vision. Requirements should include step-by-step expectations and ideas about capabilities. As technology advances, military ideas can be periodically re-evaluated. We must be able to meet the new challenges of the age, otherwise the availability of a country's armed forces and its ability to maintain security could easily be reduced. If the digital military program is based on the definition of a high level of detailed requirements, its implementation will result in the appearance of the most effective capabilities possible.

\section{References}

[1] Meeting the Energy Needs of Future Warriors. Washington, D.C., The National Academies Press, 2004. DOI: https://doi.org/10.17226/11065

[2] HARPEL, D.: Army to hot industry day for digital soldier initiative. Defense Systems Journal, 2018. www.dsjournal.com/2018/11/08/army-to-host-industry-day-for-digitalsoldier-initiative/ (Downloaded: 05.06.2020)

[3] Six Cycle Project - PCM (Figure from a conference paper entitled "Identifying under reporting issue of construction industry in Malaysia”.). ResearchGate, 2009. www. researchgate.net/figure/Six-Cycle-Project-PCM-World-Bank-Logframe-MethodologyHandbook-2009-There-are-three_fig1_305143957 (Downloaded: 05.06.2020)

[4] FARKAS, T. - HRONYECZ, E.: The Info-Communication System Requirements of the Deployable Rapid Diagnostic Laboratory Support “Sampling Group” II. AARMS, 141 (2015), 53-61.

[5] NATO Interoperability. NATO Multimedia Library, 2019. www.natolibguides.info/ interoperability (Downloaded: 05.06.2020) 
[6] NATO Policy for Standardization. International Standardization Workshop, 2018. www. dsp.dla.mil/Portals/26/Documents/Publications/Conferences/2018/2018\%20 International\%20Standardization\%20Workshop/20181030-Item6aNATOStandardizationPolicyandQuizIntlStdznWorkshop-_Myriounis. pdf?ver=2018-11-07-095044-083 (Downloaded: 05.06.2020)

[7] Future Soldier 2030 Initiative. Wired, 2009. www.wired.com/images_blogs/ dangerroom/2009/05/dplus2009_11641-1.pdf (Downloaded: 05.06.2020)

[8] FRIEDL, K. E.: Military applications of soldier phy siological monitoring. Journal of Science and Medicine in Sport, 2111 (2018), 1147-1153. DOI: https://doi.org/10.1016/j. jsams.2018.06.004

[9] STACKPOLE, B.: Keeping the Connected Soldier Connected with Simulation. DE 247 Digital Engineering, 2016. www.digitalengineering247.com/article/keeping-theconnected-soldier-connected-with-simulation/ (Downloaded: 05.06.2020)

[10] Supporting the Army’s Future Soldier Vision. UK GOV Laboratory, 2018. www. gov.uk/government/case-studies/supporting-the-armys-future-soldier-vision (Downloaded: 05.06.2020)

[11] MURRIN, D.: Defence First - A New Model for Britain's Defence Forces. 2016. www. davidmurrin.co.uk/sites/default/files/2019-08/a_new_model_for_britains_defence_forces_ october_2016.pdf (Downloaded: 05.06.2020)

[12] FIST - Future Infantry Soldier Technology System. Army Technology, 2019. www.armytechnology.com/projects/fist (Downloaded: 05.06.2020)

[13] Felin Sagem (Fantassins Equipements LIaison Intégrés) - French future infantry soldier system. Army Recognition, 2019. www.armyrecognition.com/france_french_army_military_ equipment_uk/felin_sagem_future_soldier_infantry_equipment_soldier_gear_technical_ data_sheet_specifications_uk.html (Downloaded: 05.06.2020)

[14] ARKIN, D.: The Digital Revolution of the IDF. IsraelDefense, 2016. www.israeldefense. co.il/en/content/digital-revolution-idf (Downloaded: 05.06.2020)

[15] GETTLER, L.: German military increases order for Gladius “future soldier” system. New Atlas, 2013. https://newatlas.com/future-soldier-rheinmetall-gladius/26271/ (Downloaded: 05.06.2020)

[16] STEPANSKY, A.: OPED: new conformal batteries expedite moves to a digital soldier. Defense Systems, 2017. https://defensesystems.com/articles/2017/10/cw/soldier-batteriesarmy.aspx (Downloaded: 05.06.2020)

[17] Land Warrior Rig. Jack O' Lantern's MS Blog, 2017. http://jackolanternsmshblog.blogspot. com/2017/05/land-warrior-rig.html (Downloaded: 05.06.2020) 